\title{
DETERMINATION OF HYDROGEN PEROXIDE IN REACTOR MODERATOR SOLUTIONS BY FLOW INJECTION ANALYSIS (U)
}

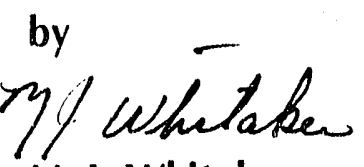

M. J. Whitaker

\section{DISCLAIMER}

This report was prepared as an account of work sponsored by an aran $\%$ of the United States Government. Neither the United States Government nor any agency thereof, nor any of their employees, makes any warranty, express or implied, or assumes any legal liability or responsibility for the accuracy, completeness, or usefulness of any information, apparatus, product, or process disclosed, or represents that its use would not infringe privately owned rights. Reference herein to any specific commercial product, process, or service by trade name, trademark, manufacturer, or otherwise does not necessarily constitute or imply its endorsement, recommendation, or favoring by the United States Government or any agency thereof. The views and opinions of authors expressed herein do not necessarily state or reflect those of the United States Government or any agency thereof.

\section{Westinghouse Savannah River Company}

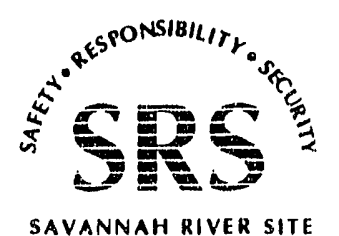


The information in this article was developed during the course of work under Contract No. DEAC09-89SR18035 with the U. S. Department of Energy. 


\title{
DETERMINATION OF HYDROGEN PEROXIDE IN REACTOR MODERATOR SOLUTIONS BY FLOW INJECTION ANALYSIS (U)
}

\begin{abstract}
A flow injection analysis (FIA) method for the determination of hydrogen peroxide in reactor moderator water was developed and installed at the Savannah River Site (SRS) Water Quality Laboratory. The technique has an analytical range of 0.10 to $2.50 \mathrm{ppm}(\mathrm{ug} / \mathrm{mL})$ with a sampling rate of 40 samples per hour. The calibration curve is linear with a correlation coefficient of 0.999 , and the precision is excellent with relative standard deviations at the $0.50 \%$ level for both 0.10 and $2.50 \mathrm{ppm}$ standards. When the automated FIA procedure is compared to the manual method it demonstrates a twenty minute reduction in analysis time per sample, and the total liquid waste generated per sample analyzed is reduced Ly roughly $95 \mathrm{~mL}$.
\end{abstract}

\section{INTRODUCTION}

This is the second FIA method to be installed at the Water Quality Laboratorythe first procedure was for the determination of boron. The two automated systems (boron and hydrogen peroxide) were designed and integrated so that switching from one method to the other is a simple task accomplished within a matter of a few minutes.

The FIA hydrogen peroxide procedure will replace the current manual method, which requires 20 to 30 minutes analysis time per sample. The flow injection analyzer is fully automated, and once the samples have been placed in the autosampler and the analyzer initiated the samples are analyzed. The results are then displayed on a hard copy printout. The FIA system will improve confidence and reliability in data results by reducing experimental and human error to which manual procedures of sample analysis are inherently susceptible. This automated FIA procedure, when compared to the manual method, will improve the safety factor of sample handling by reducing the amount of time the analyst is in contact with samples. The use of this FIA technique is also advantageous because less total volume of sample and reagent waste is generated than with the manual method. This reduces the waste handling and disposal problem.

The FIA technique is based on the introduction of a well-defined sample volume (58 microliters) into a continuous flowing stream of $1 \%$ sodium chloride. Once injected, the sample bolus is then carried through a flow cell in an electrochemical detector, which amperometrically measures the hydrogen peroxide present in the sample.

\section{DISCUSSION}

\section{Reagents and Standards}

All reagents and standards were of analytical-reagent grade quality, and prepared in distilled, deionized water from a Nanopure system (Barnstead / Thermolyne).

A $1 \%$ solution of sodium chloride (Mallinckrodt CAS\# 7647-14-5) was pre- 
pared by dissolving 10 grams into one liter of deionized water. This solution was used as the carrier stream to move the sample through the FIA system. It also served as an electrolyte for the electrochemical (EC) detection system.

Stock and working standards were prepared from a 3\% solution of hydrogen peroxide (Fisher Scientific CAS\# 7722-84-1) by adding the appropriate volume to each standard volumetric container, and diluting the solution with deionized water. Once standards were prepared, all the solutions were refrigerated when not in use to reduce degradation. The analytical range for this procedure was 0.10 to 2.50 parts per million (ppm, ug/mL) hydrogen peroxide.

\section{Instrumentation}

The flow injection analyzer and instruments used for this developmental work were Fiatron modular units. Each system included an SC-110 autosampler with 120 sample capacity, an FIA-Valve 2000 eight port sample injection valve with a 58 microliter sample loop, an FIA-Pump six channel peristaltic pump, and a master control module with an FIA-Zyme amperometric detection drawer. The chromatographic peaks were collected on a Cole-Parmer 100-millimeter-strip chart recorder, and a hard copy of the data results was printed on a Brother M-1109 dot matrix printer. A schematic diagram of the flow injection manifold system is shown in Figure 1.

The master module was the microprocessor controller of the FIA system where various timing parameters, and sample and standard information were programmed anci stored for each method. The masic: module was designed to accommodate several different types of detection techniques, but only one detection device was functional at a time. The FIA-Zyme amperometeric detector was the electrochemica: technique used in the hydrogen peroxide method discussed here. This detection device was slightly altered to improve sensitivity, and to make it more suitable for this development project.

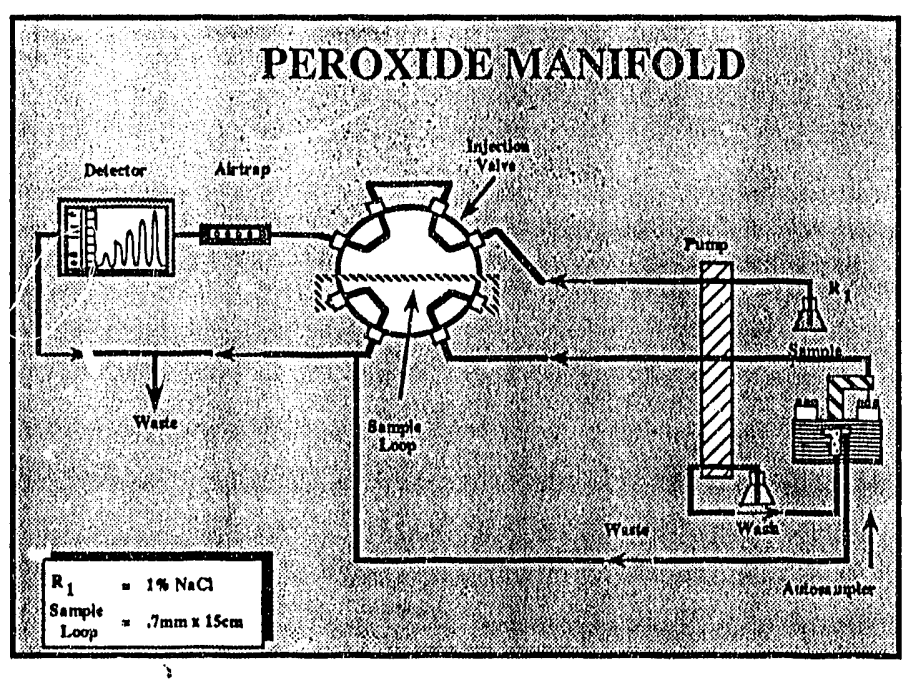

Figure 1

Figure 2 shows a backside view of the FIA-Zyme flow cell. The carrier stream enters the cell, flows over the surface of the probe, then exits to waste. A detailed cut-away view of the amperometric probe, membranes, and a frontside view of the flow cell is shown in Figure 3. The surface of the probe is silver/silver chloride construction. When allowed to soak in $1 \% \mathrm{NaCl}$ solution (carrier stream) overnight before it's used the following day, it demonstrates better stability, and shorter equilibration time at startup.

Hydrogen peroxide is a radiolysis by-product in reactor moderator water that can be measured directly in the collected 


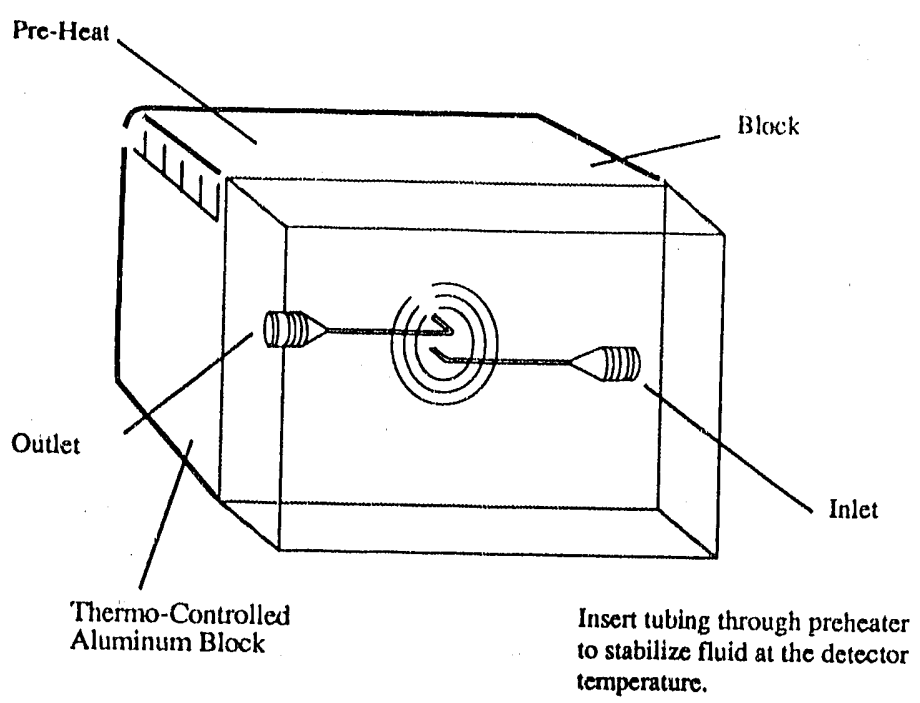

Figure 2. FIA-ZYME Flow Cell

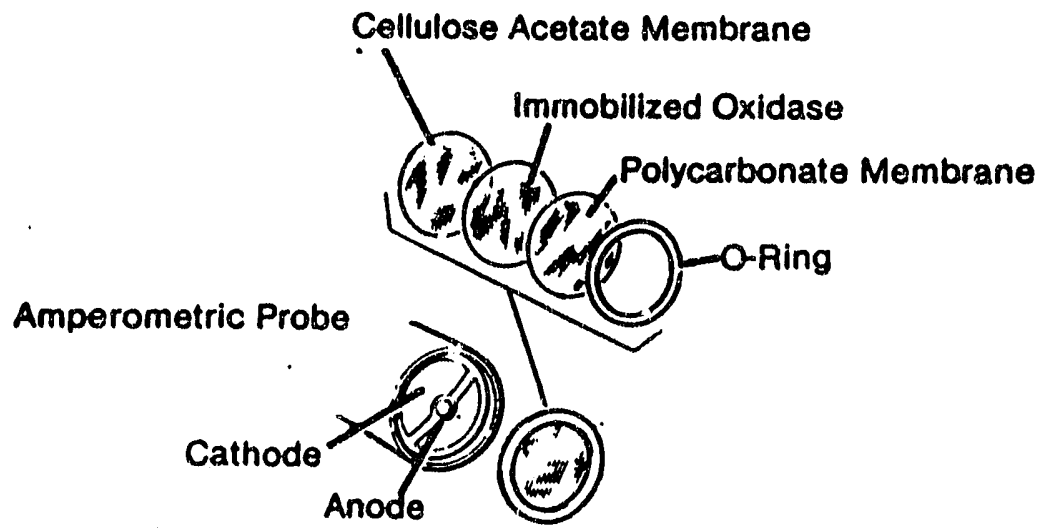

Figure 3. Membrane Detail samples. Therefore, it's not necessary to use the immobilized enzyme membranes to generate hydrogen peroxide. They were removed from the probe, and only the o-ring remained to prevent leakage in the system. Also, it was determined when using only blank membranes (polycarbonate membranes without the enzyme) that sensitivity varied dramatically, which was probably due to variation in the thickness of different membranes (see Figure 3). Sensitivity improved considerably, and was more consistent, once the membranes were removed.

This detection device was actually designed to analyze various types of sugars. The sugar molecules react with a specific enzyme immobilized on the surface of a membrane (see Figure 3) to produce hydrogen peroxide as a reaction product, which is subsequently measured by the amperometric probe. The potential of the probe was preset at the factory at -0.70 volts.

\section{RESULTS}

\section{Flow Rate Study}

A constant flow rate is a key parameter in the flow injection analysis technique, and is controlled by the size of the pump tubing and speed of the peristaltic pump. The pump tubing used in this procedure, for both the sample and carrier stream conduits, was Tygon TM tubing with a 1.02 $\mathrm{mm}$ I.D., and color coding of white/white.

The pump speed and size of the pumip tubing not only controls the flow rate, but also affects the analysis rate, sample rate, and response factor of the analyzed sample or standard. Table I lists the data from a series of experiments where the pump speed was increased from $14 \%$ to $40 \%$. The flow 
rate, analysis rate, sample rate, and the response of a $2.00 \mathrm{ppm}$ standard were observed and analyzed.

\section{Table I}

$\begin{array}{ccccc}\begin{array}{c}\text { Pump } \\ \begin{array}{c}\text { Speed } \\ \text { (\%) }\end{array}\end{array} & \begin{array}{c}\text { Flow } \\ \text { Rate } \\ \text { (mL/min) }\end{array} & \begin{array}{c}\text { Analysis } \\ \text { Rate } \\ \text { (min/sam) }\end{array} & \begin{array}{c}\text { Sample } \\ \text { Rate } \\ \text { (sam/hr }\end{array} & \begin{array}{c}\text { Response } \\ \text { (Rel. Units) }\end{array} \\ 14 & 0.70 & 3: 36 & 17.00 & 108,960 \\ 18 & 0.90 & 3: 05 & 19.00 & 107,740 \\ 22 & 1.10 & 2: 30 & 24.00 & 100,900 \\ 24 & 1.20 & 2: 15 & 27.00 & 96,400 \\ 26 & 1.30 & 1: 59 & 30.00 & 95,200 \\ 28 & 1.40 & 1: 51 & 32.00 & 85,700 \\ 30 & 1.50 & 1: 44 & 35.00 & 85,000 \\ 32 & 1.60 & 1: 40 & 36.00 & 82,200 \\ 34 & 1.70 & 1: 35 & 38.00 & 81,200 \\ 36 & 1.80 & 1: 30 & 40.00 & 78,600 \\ 38 & 1.90 & 1: 21 & 44.00 & 75,500 \\ 40 & 2.00 & 1: 16 & 47.00 & 73,600\end{array}$

Figure 4 graphically illustrates the effects of pump speed when response versus flow rate is plotted. In this experiment the flow rate ranged from $0.70 \mathrm{~mL} / \mathrm{min}$ to $2.00 \mathrm{~mL} / \mathrm{min}$, with the corresponding responses ranging from 108,960 to 73,600 relative units. Note

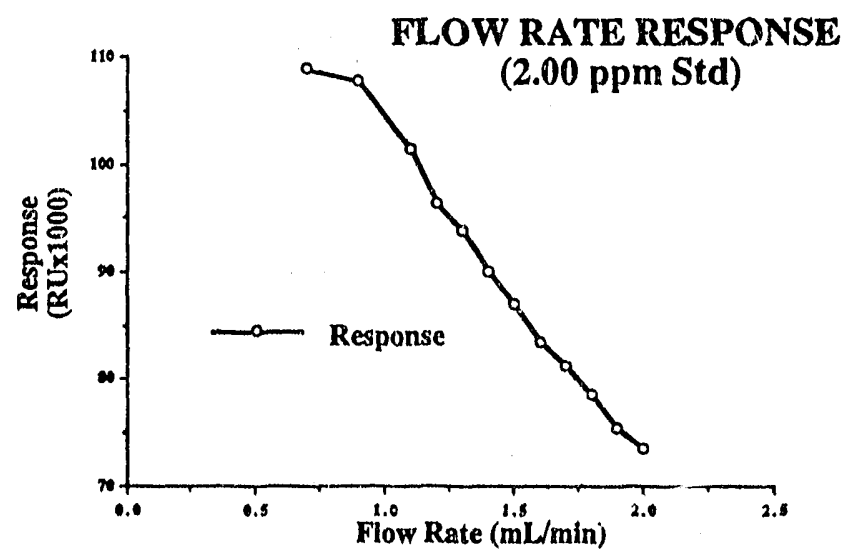

Figure 4 that when the flow rate was increased the response decreased even though the same volume of standard was introduced into the FIA system for all flow rates. As the flow rate increased less time was available for hydrogen peroxide molecules to make contact with the surface of the amperometric probe; thus, less response was generated and observed.

The analysis rate is defined in this report as the length of time required to analyze one sample or standard. This period of time includes sample loop loading, injection of the sample into the carrier stream, and the return to baseline at a preset threshold. Figure 5 is a plot of the analysis rate versus the flow rate. The analysis rate ranges from 3:36 to $1: 16$ minute per sample, and the range of flow rate is the same as above (see Table I). Again, a negative slope curve is demonstrated-as the flow rate increases the time required to analyze each sample (plotted as sec/sam) decreases.

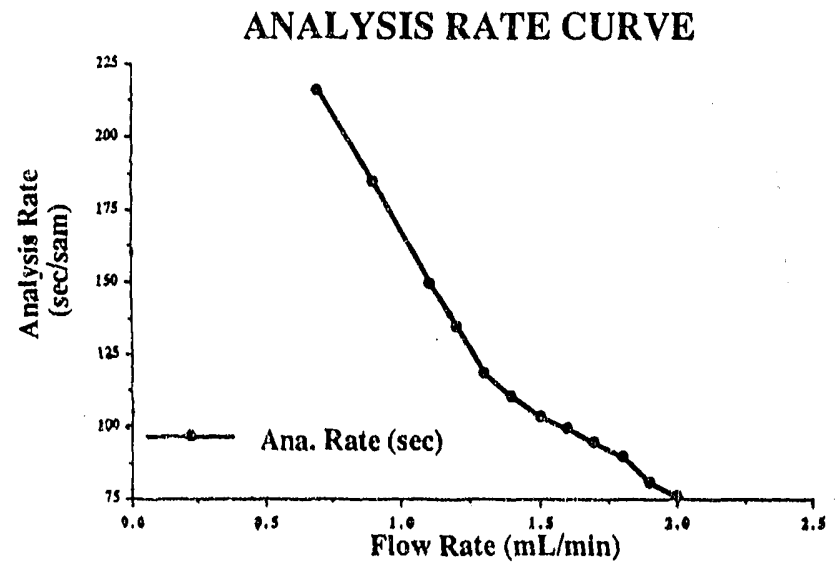

Figure 5 
The number of samples analyzed in one hour is defined as the sample rate. Again, as the flow rate changes it has a direct impact on the sampling rate. In this case, as the flow rate increases so does the sampling rate. Figure 6 illustrates this when the sampling rate versus flow rate is plotted. The sampling rate ranges from 17 to 47 samples jer hour, and the flow rate range is the same as above (see Table I).

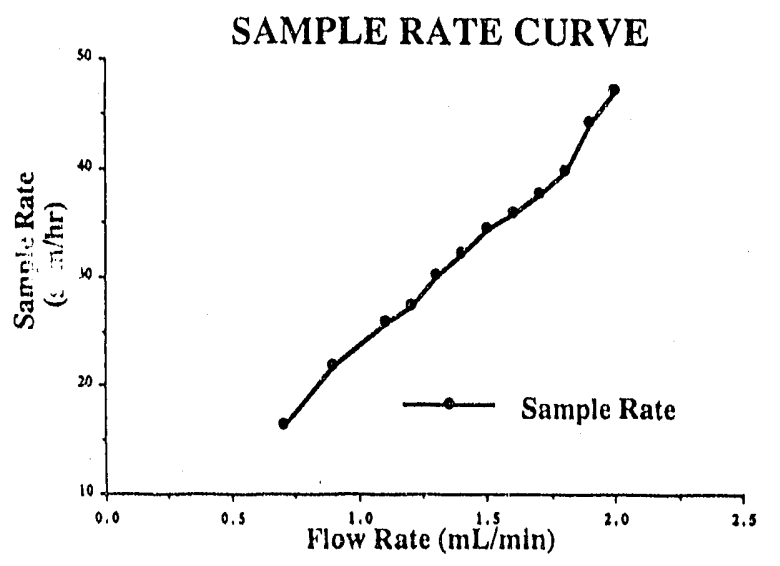

Figure 6

There are many reasons to automate sample analysis, when possible. One of the most obvious reasons is the reduction in man hours over accomplishing the same job manually. To analyze one sample by the manual procedure at the Water Quality Laboratory requires 20 to 30 minutes, according to lab personnel. If one takes the average manual analysis time per sample (25 minutes) and compares it to the automated FIA analysis time per sample at different flow rates, the amount of time saved can be graphically dernonstrated as the flow rate changes. For a flow rate of 0.70
$\mathrm{mL} / \mathrm{min}$ the time savings value is calculated as follows:

manual time - FIA time $=$ time saved

Substiturion yields:

$(1500 \mathrm{sec}-216 \mathrm{sec}=1284 \mathrm{sec})$

Results of the time savings calculations are listed in Table II, and graphically illustrated in Figure 7. When time savings data versus flow rate is plotted, a positive slope is demonstrated indicating that as flow rate increases time savings also increases. The minimum time saved by the flow injection analysis technique at a flow rate of 0.70 $\mathrm{mL} / \mathrm{min}$ is $21: 24$ minutes, and the maximum time saved is $23: 44$ minutes when the flow rate is $2.00 \mathrm{~mL} / \mathrm{min}$ (see Table II).

\section{Table II}

$\begin{array}{cccc}\begin{array}{c}\text { Flow Rate } \\ \text { (mL/min) }\end{array} & \begin{array}{c}\text { Analysis Rate } \\ (\mathrm{min} / \mathrm{sam})\end{array} & \begin{array}{c}\text { Time Saved } \\ \text { (sec/sam) }\end{array} & \begin{array}{r}\text { Time Saved } \\ \text { (mim/sam) }\end{array} \\ 0.70 & 3: 36 & 1284 & 21: 24 \\ 0.90 & 3: 05 & 1315 & 21: 55 \\ 1.10 & 2: 30 & 1350 & 22: 30 \\ 1.20 & 2: 15 & 1365 & 22: 45 \\ 1.30 & 1: 59 & 1381 & 23: 01 \\ 1.40 & 1: 51 & 1389 & 23: 09 \\ 1.50 & 1: 44 & 1396 & 23: 16 \\ 1.60 & 1: 40 & 1400 & 23: 20 \\ 1.70 & 1: 35 & 1405 & 23: 25 \\ 1.80 & 1: 30 & 1410 & 23: 30 \\ 1.90 & 1: 21 & 1419 & 23: 39 \\ 2.00 & 1: 16 & 1424 & 23: 44\end{array}$

TIME SAVINGS CURVE

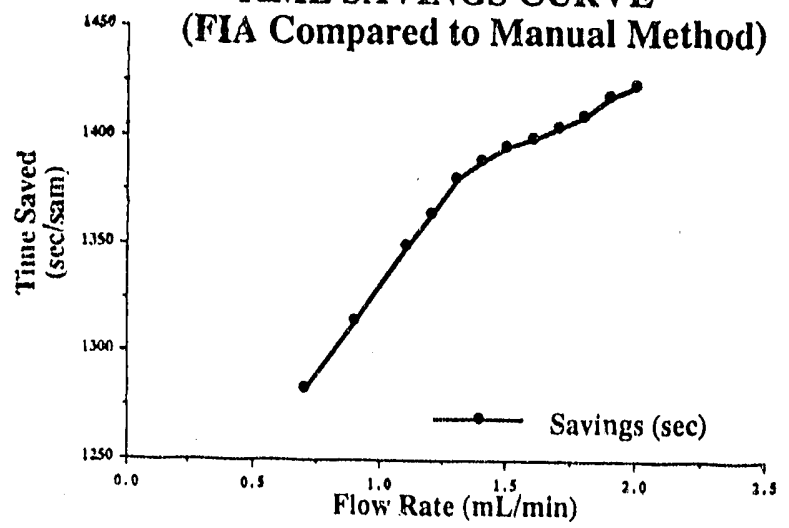

Figure 7 


\section{Sample Volume Study}

The sample injection volume was varied by changing the length of the sample loops, which were constructed from $1 / 16$ inch Teflon ${ }^{\mathrm{TM}}$ tubing that had a $0.7 \mathrm{~mm}$ I.D. The flow rate was set at $1.80 \mathrm{~mL} / \mathrm{min}$. The results of analyzing various sample injection volumes of a $2.50 \mathrm{ug} / \mathrm{mL}$ hydrogen peroxide standard is graphically displayed in Figure 8, and the data is listed in Table III.

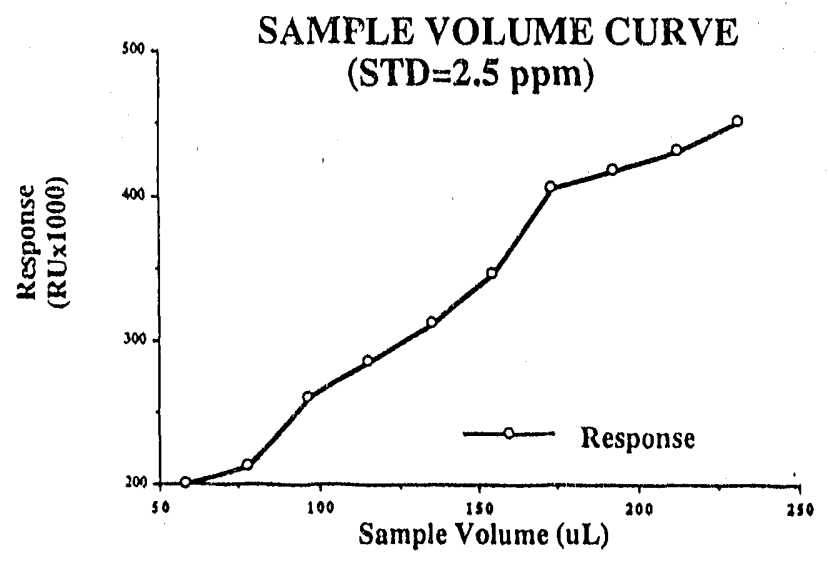

Figure 8
As expected, when the volume of analyzed standard increases, the response also increases with each incremental increase in volume. Note that as the sample volume increases so does the analysis rate (the amount of time to analyze one sample). Therefore, a tradeoff between sensitivity and analysis rate is created. The increased analysis rate is due to longer periods of time required to flush out the larger volumes of standard introduced into the flow cell.

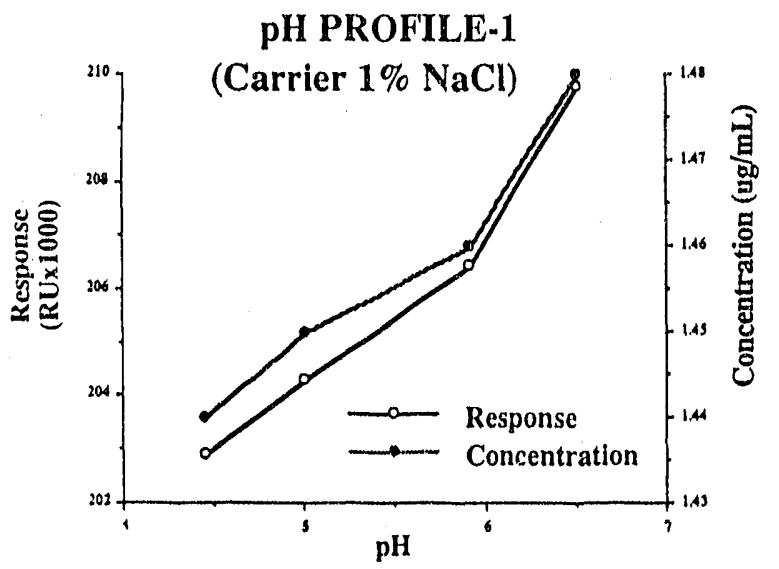

Figure 9

Table III

\begin{tabular}{ccc}
$\begin{array}{c}\text { Sample Loop } \\
(\mathrm{cm})\end{array}$ & $\begin{array}{c}\text { SampleVolume } \\
(\mathrm{UL})\end{array}$ & $\begin{array}{c}\text { Response } \\
\text { (Rel Units) }\end{array}$ \\
\hline & & \\
15 & 58 & 201,000 \\
20 & 77 & 213,400 \\
25 & 96 & 261,600 \\
30 & 115 & 286,200 \\
35 & 135 & 312,900 \\
40 & 154 & 347,600 \\
45 & 173 & 406,500 \\
50 & 192 & 418,900 \\
55 & 212 & 432,300 \\
60 & 231 & 452,400
\end{tabular}

Because of the improved sensitivity by removing the probe membrane it was not necessary to use large volumes of standards or samples in this procedure. As a result, the $15 \mathrm{~cm}$ sample loop was sufficient, and it was used for the remaining developmental work. The hydrogen peroxide procedure installed at the laboratory was likewise equipped. 


\section{pH Effects}

The ideal operating $\mathrm{pH}$ range for reactor moderator water is 4.60 to 4.80 . To determine if the procedure would function satisfactorily at these $\mathrm{pH}$ levels, a pH study was conducted in the development of this project. A $1.44 \mathrm{ug} / \mathrm{mL}$ hydrogen peroxide standard has a measured $\mathrm{pH}$ of 4.45 , and the carrier stream (1\% NaCl solution) for this procedure has a $\mathrm{pH}$ of 6.57 . The $\mathrm{pH}$ of the $1.44 \mathrm{ug} / \mathrm{mL}$ standard was adjusted from 4.45 to 6.50 , and analyzed after each adjustment to monitor what effects this narrow range in pH might have on the FIA detection system. The results of the $\mathrm{pH}$ experiments are listed in Table IV, and graphically illustrated in Figure 9.

\section{Table IV

\begin{tabular}{lll} 
pH & $\begin{array}{l}\text { Response } \\
\text { (RelUnits) }\end{array}$ & $\begin{array}{l}\text { Conc. } \\
\text { (ug/mL) }\end{array}$ \\
\hline 4.45 & & \\
5.00 & 202,931 & 1.44 \\
5.90 & 204,307 & 1.45 \\
6.50 & 206,458 & 1.46 \\
& 209,789 & 1.48
\end{tabular}

At first glance, Figure 9 gives the impression that $\mathrm{pH}$ is a critical factor in the measurement of hydrogen peroxide by the electrochemical mode of detection. After closer examination, note that the difference in response from $\mathrm{pH} 4.45$ to 6.50 is 6867 relative units. This corresponds to a concentration value of only $0.04 \mathrm{ug} / \mathrm{mL}$, which is considerably less than the lowest calibration standard $(0.10 \mathrm{ug} / \mathrm{mL})$. It was concluded that $\mathrm{pH}$ has little effect on the amperometric detection used for this FIA system.

\section{Calibration and Reproducibility}

The analytical range of this procedure consisted of seven standards ranging from 0.10 to $2.50 \mathrm{ug} / \mathrm{mL}$ hydrogen peroxide. All standards were prepared as described in the discussion section of this document. No probe membranes were used, the flow rate was set at $1.30 \mathrm{~mL} / \mathrm{min}$, and the surface of the probe was cleaned and prepared when these calibration results were generated. The data is recorded in Table V., and Figure 10 demonstrates the linearity of the calibration curve, which has a corresation coefficient of 0.999

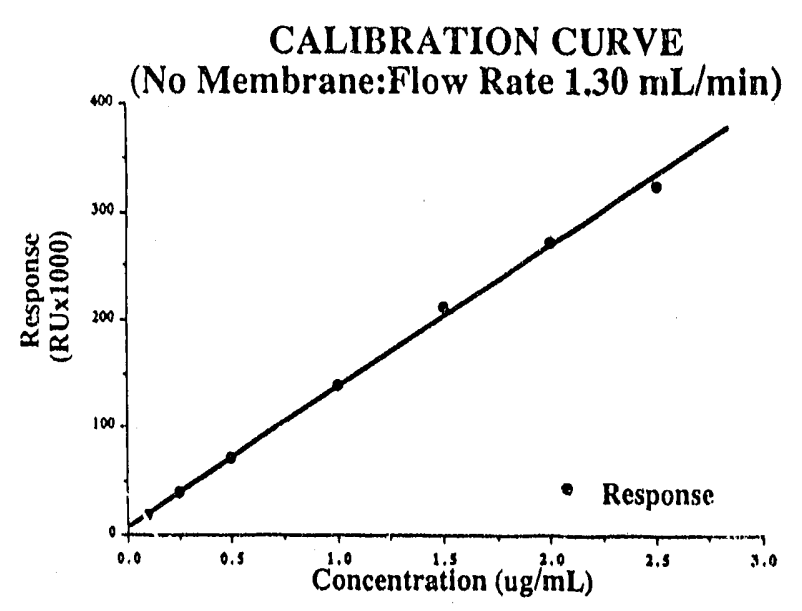

Figure 10

\section{Table V}

$\begin{array}{cc}\begin{array}{l}\text { Conc. } \\ \text { (ug/mL) }\end{array} & \begin{array}{c}\text { Response } \\ \text { (Rel.Units) }\end{array} \\ 0.10 & 19200 \\ 0.25 & 40448 \\ 0.50 & 72576 \\ 1.00 & 138,880 \\ 1.50 & 212,352 \\ 2.00 & 271,104 \\ 2.50 & 325,120\end{array}$

The precision of this procedure was excellent with relative standard deviations 
of $0.52 \%$ for a $0.10 \mathrm{ug} / \mathrm{mL}$, and $0.48 \%$ for a $2.50 \mathrm{ug} / \mathrm{mL}$ standards. Each standard was analyzed five times, and the results of the statistical data are listed in Table VI.

\section{Table VI}

\begin{tabular}{lll} 
& $0.10 u \mathrm{~g} / \mathrm{mL}$ STD & $2.5 \mathrm{ug} / \mathrm{mLLSTD}$ \\
\hline Ave & 17,407 & \\
SD & 90.53 & 202,714 \\
RSD & $0.52 \%$ & 684 \\
n & 5 & $0.33 \%$ \\
& & 5
\end{tabular}

\section{CONCLUSION}

The FIA procedure at the SRS Water Quality Laboratory demonstrated good linearity and precision in the analytical range requested from lab personnel. A sampling rate of 40 samples per hour and a hydrogen peroxide concentration of 10 to 2.50 ppin was achieved. The FIA system proved simple to operate, and reasonably maintenance-free when the proper preventative measures are applied.

This automated flow injection system, when compared to the manual method for hydrogen peroxide determination, reduces man hour requirements of analysis time significantly-in many cases over 20 minutes per sample. Another important aspect of this automated procedure over the manual method is the reduction of analyst contact with samples during the analysis process. Plus, the total volume of sample and reagent waste generated are both reduced dramatically by this FIA procedure.

\section{BIBLIOGRAPHY}

(1) Fiatron, Inc., Flow Injection Analyzer Manual, "Automated Sample Prep".

(2) Fiatron, Inc., Technical Application Notes, "Peroxide (Active Oxygen) In Process Streams", (1986).

(3) Kutt, J. C., Vohra, S. J., American Lab., Dec., (1983).

(4) Chen, L., Lin, M.S., Hara, M., Rechnitiz R.C., Anal. Let., 24(1), 1-14, (1991).

(5) Genfa, Z., Dasgupta, P.K., Edgemond, W.S., Marx, J.N., Anal. Chim. Acta, 243, 207-216, (1991).

(6) Clapp, P.A., Evans, D.F., Anal Chim. Acta, 243, 217-220, (1991). 

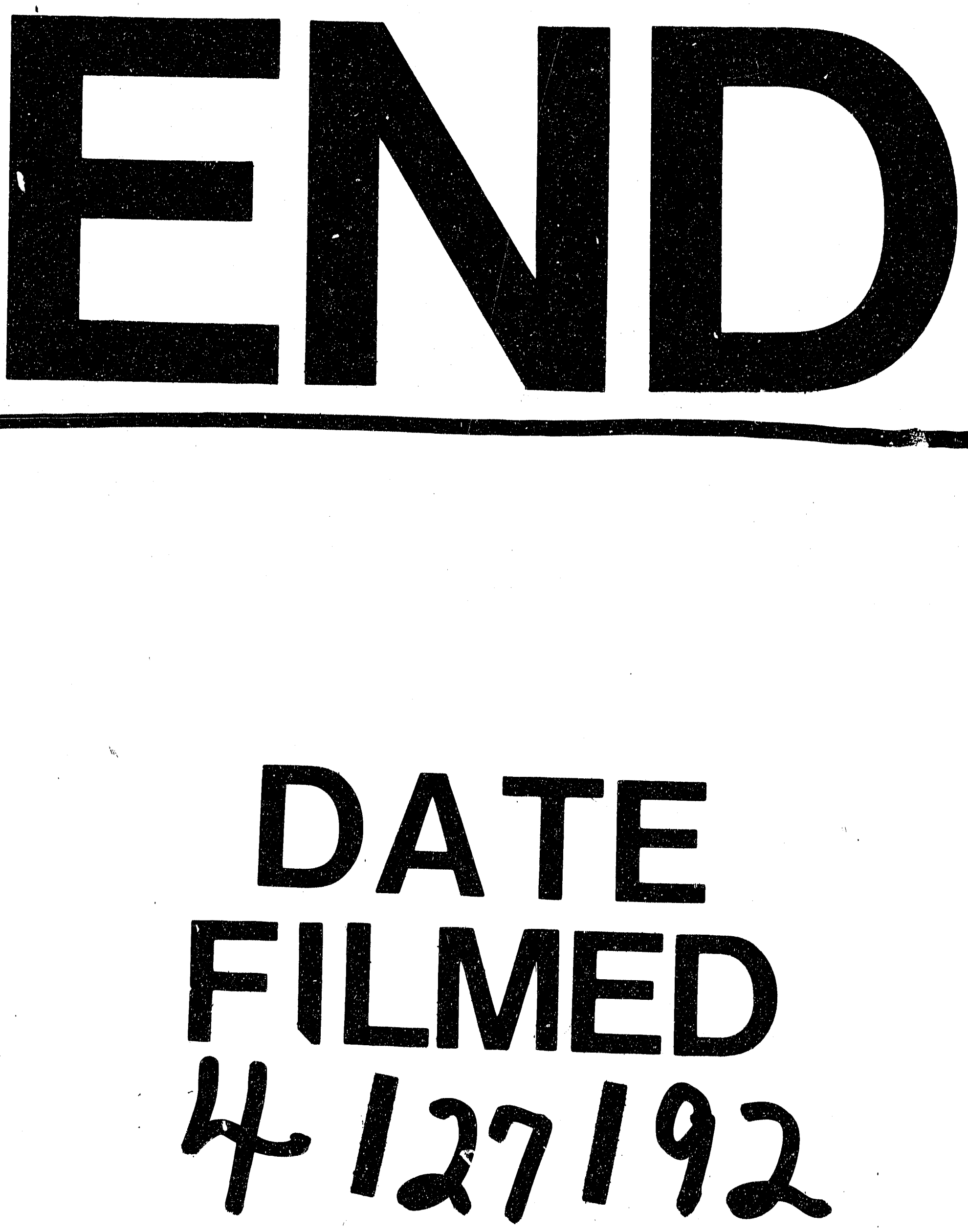


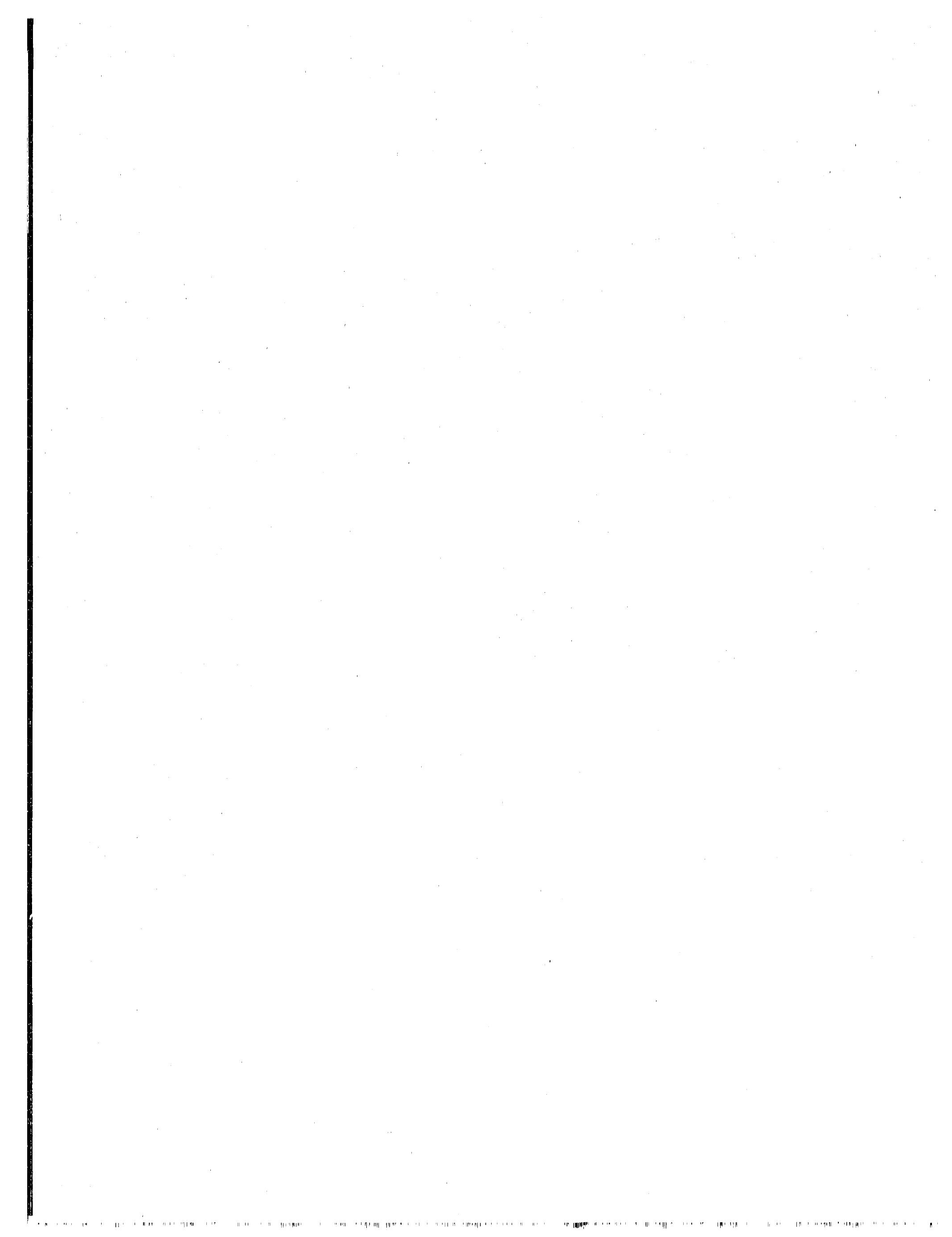

